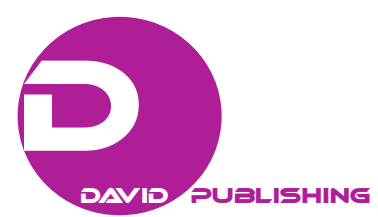

\title{
A Proposal for a New Hotel-Style Nursing Home Management System in China
}

\author{
Yangzi Yuanyi, Takashi Kondoh \\ Aichi Institute of Technology, Aichi, Japan
}

\begin{abstract}
China is currently classified as an aging society. It is predicted that by 2050, the elderly population in China will exceed 400 million, and the problem of China's aging population is becoming more serious. Simultaneously, due to an increase in population migration, many young people went out to work, resulting in an increase in the number of “empty nester” households and elderly people living alone. Even if the children of these families are employed locally, they are often too busy to take care of the elderly. Furthermore, the number of institutions for the aged falls far short-from meeting the needs of the elderly, and the relatively closed-off management methods of existing facilities make the elderly lonelier. Many facilities are based on centralized dormitory-style living and there are no customized services for the needs of the elderly. This study aims to innovate a new type of pension model, utilizing the guidance of government agencies, integrated social resources, community resources, and family resources. The aim is to provide the elderly with life care and spiritual comfort based on home-based nursing services, simultaneously addressing the concerns of their children. The proposal for a new type of hotel-style apartment nursing home aims to use modern information technology to realize the concept of home-based care, so that the elderly can enjoy professional services tailored to their needs. The proposal is also based on information from the elderly and a general hotel chain model, with the aim of fulfilling daily care needs of the elderly, establishing information files, setting up a comprehensive service center, and realizing the standardization of service for the aged and standardization of service quality assessments. As a service and management institution for a home-based pension model, the management completes the service for the elderly through a virtual nursing home chain service system, simultaneously realizing effective management of the franchise store and service staff. The home care virtual nursing home service system will have a call center as the front end and the software platform as the core, and will implement standardized services through customized processes. We then adjusted the proposal by questionnaire and combine it with the experience of existing pension services. The above steps finally led to a proposal for a new type of hotel-style apartment nursing home.
\end{abstract}

Keywords: abstract, preparing a manuscript, writing skills, grammar

\section{Background, Objectives, and Goals}

The Chinese government implemented the "one-child" policy in the 1980s. Therefore, the family form in

Yangzi Yuanyi, M.S (Design), Ph. D. candidate, Graduate School of Business Administration and Computer Science, Aichi Institute of Technology, Aichi, Japan.

Takashi Kondon, Ph.D. (Engineering), professor, Faculty of Business Administration, Aichi Institute of Technology, Aichi, Japan.

Correspondence concerning this article should be addressed to Yangzi Yuanyi, Jiyugaoka 2-49-2, Chikusa-ku, Nagoya 464-0044, Japan. 
China at the moment generally consists of three generations-from grandparents to grandchildren — of four grandparents, two parents, and one child. At the end of 2016, the number of elderly people in China reached $16.7 \%$ of the total population, and the number of elderly people who need care has gradually increased. This leads to the current situation of inadequate care for the elderly. China is the only country in the world with more than 100 million elderly people. The matter of old-age care is a severe test of society, and although the government has expended a large amount of human and financial resources on service agencies of the elderly, it is difficult to balance all the aspects, such as the medical system. These difficulties have led to a large number of social problems, which have seriously affected the development of the country. Some developed countries have adopted perfect welfare concerning the issue of old-age care and have spent a considerable amount of money. However, China as a developing country cannot blindly follow the systems implemented by these developed countries, since it cannot be adapted to the conditions in China. China has certain special characteristics concerning culture and economy, and our concept of old-age care is gradually changing, as can be seen from the annual increase in nursing homes in China. Compared to 2009, the increase in nursing home service agencies is faster by nearly one third, meaning that more and more elderly people in both urban or rural areas have access to aged care services. Therefore, the traditional Chinese concept of each living unit being a big family and that old-age services should be provided by their children are already changing.

The Chinese government has always attached great importance to the issue of elderly care. In December 2011, the General Office of the State Council issued the "Social Pension Service System Construction Plan (2011-2015)”, which focuses on promoting the construction of a medical care pension society. In 2013, the State Council distributed a number of documents on accelerating the development of the aged care service industry that explicitly mention encouraging social services to organize large-scale and chain-oriented nursing homes that is based on a hotel chain business model and that uses decentralized and centralized management and operates in a professional, standardized, and informational manner, which is conducive to the growth of the service network. In February 2015, 10 departments—including the Ministry of Civil Affairs—jointly issued the "Implementation Opinions on Encouraging Private Capital to Participate in the Development of the Aged Care Service Industry”. The participation of private companies in the aged care service provides the government with support, and a variety of attempts have been made to establish private pension institutions. For example, in June 2010, the Harbin Civil Affairs Bureau and the Office of the Aged Work Committee actively guided social services to establish Harbin Bonny Senior Service Co., Ltd., the first chain care institution in Harbin and the first of 11 small-scale nursing home service institutions in the Daoli District of Harbin. Dalian City has also developed an interactive remote care service center through the Dalian Civil Affairs Bureau. The main services offered include organizing the elderly to participate in suburban leisure pensions and off-site tourism pensions. This new interactive remote pension model can help the elderly to choose their own nursing homes across the entire country, and can be realized through the curtailing of national pension institutions. For example, a national pension service platform and network can be constructed to assist the elderly in partaking in leisure activities and holidays, to travel and sightsee, and to treat diseases. A similar timeshare model was presented by Yunxiang Xianju in Yunnan Province and Cheng Xianju in Zhejiang Province. They built a hotel-style nursing home according to the standards of a five-star hotel; it is a comprehensive old-age club that integrates apartments, villas, hotels, and clubs. The company signed an agreement with the villagers to renovate buildings to a uniform standard, and the Lianzhong Company has a 30-year right to use and operate from the rooms. This user right will be returned to the villagers upon expiration. 
These various examples old-age care institutions allow us to see the particulars of China's old-age care institutions. China is a country with diverse geographical conditions and a large number of different populations. There are also diverse forms of capital available, and China's social welfare system-as a developing country-is improving. Many private companies are aiming to invest capital during the current "gold" development period of the old-age market in the context of rapid economic development, and these companies are playing an increasingly important role. There are, however, also various problems in addition to all the benefits. For example, it is difficult to establish uniform standards for old-age institutions, since regional pension policies cannot be adhered to nationwide. Presently, the medical insurance system cannot keep up with the changes in the disease status of the elderly, and there is a lack of specialized drugs and reasonably-priced drugs for existing high-risk diseases. Therefore, this study will conduct a comprehensive questionnaire survey concerning these pension issues that concerns the general public most and that truly reflects the more prominent contradictions of today's social pension issues in China.

\section{Methods}

For the background information survey, as well as the previous studies on Chinese elderly population, we use data gathered to carry out a SWOT (strengths, weaknesses, opportunities, and threats) analysis after the comprehensive analysis. A SWOT analysis is a qualitative method that is combined with an AHP (analytic hierarchy process) application in the process of strategic choice and strategic evaluation to research and judge all the factors that need to be considered in the proposal of the new hotel-style nursing home chain. A stratification analysis is carried out to address the problems associated with the new type of hotel-style nursing homes, and the concerns raised by the existing literature that studied the complexities of China's issues concerning services for the aged. We also address the different concepts and experts' understanding, controlling for the possibility of their one-sidedness, in order to test the reasonableness of the results obtained. Next, we check the consistency of the judgment matrix to make it reasonable. A questionnaire containing 54 questions is then produced to assess future elderly population problems of public concern. This questionnaire survey was conducted nationwide. Of the 500 copies that were issued, 240 valid completed questionnaires were collected. The questions mainly focused on the respondents' perceptions of their parents' ways of providing for the elderly, as well as their intentions for future support for themselves. By analyzing the results of the questionnaire survey, we hope to improve the analysis of the current services for the aged problem.

\section{Results}

The proposed new chain hotel-style nursing home will adopt a five-star hotel management method to reduce the interruption to the elderly members. The concept is that there is no staff in the apartment, which is different from traditional nursing homes that do not necessarily focus on the privacy of senior citizens, leading to difficulties in controlling the quality of services. The proposed nursing home will offer specialized interiors and accessibility systems for the older residents of the centralized dormitory-style living. An example is voice-activated wall-mounted appliances, which ensures practicality and are specially designed for the aged, providing the elderly staying in the home with the same comfort and the undisturbed privacy. Simultaneously, the hotel-style nursing home chain will adopt a nationwide unified reservation and pick-up service, enabling members to plan their travels in advance, should they choose to. An important aspect of this mode of travel will be data management; it will be managed by big data for every step of the journey, eliminating the possibility of 
human error. Information, such as weather and warnings concerning natural disasters at travel destinations will be sent to members in advance by mobile phone or mail, providing a truly exclusive service for senior citizens. Furthermore, each member's unique situation will be catered for through the unified management of personal preference data, which can be utilized to plan travel routes suitable for members by using big data. This will also increase the membership recognition of the new hotel-style nursing home chain, increasing sales through membership promotion and recognition. Specifically, the following three points are addressed.

\section{Handling Procedures}

The results of the SWOT-AHP ST standard concerning the establishment of a training department to improve employees' skills through continuous training; introducing advanced technology in the IOT (Internet of Things) field, such as RFID (radio-frequency identification) technology, face recognition, GPS positioning and the like. To build healthy big data is a particularly important element of the program. Therefore, the data of each consumer who joins the new hotel-style nursing home chain are registered in the form of a membership profile. This data can be implemented for procedures, such as face recognition, making it convenient to contact other members without having to submit relevant identification certificates. One can merely log into the medical insurance card system to facilitate cash settlement when medical problems occur. This also dispenses with the bracelet. The role of the bracelet is identification, but with the face recognition system all aspects of health can be tested during their stay. If any abnormal data are detected, the local data center library automatically alerts the staff to contact the member to determine their safety and health status. Additionally, a grading system is adopted and members can be managed individually according to the services needed. Different levels of service will be available to help provide better and more personalized service based on members' needs. At the same time, the service can be individually customized to provide special services according to the special demands of members, for example to provide transportation and a 24-hour personal service to members with mobility impairments. The centralized dormitory-style living quarters are accessible to the elderly, the lighting system is operated by the sensing device inside the room, and the sound control system is adapted for the entertainment unit. A user panel is especially designed and incorporated for all buttons to minimize the risk of a protruding metal design, so that the elderly can use it comfortably and easily.

\section{Management Characteristics of New Hotel-Style Nursing Home Chain}

The chain model of the proposed nursing home will consist of headquarters that directly operates the entire chain of the hotel-style nursing home or by direct investment, managing various different chains of nursing homes, constituting a chain network. In the SWOT-AHP analysis under the SO standard, a unified service agreement, a unified logo, and a unified service image, services will be standardized and new types of hotel-style pension apartment management models can be explored for standardized operations. The proposed hotel-style chain will enable members to travel between geographically different cities and natural climates while simultaneously achieving the prevention of seasonal diseases. Additionally, the formation of a model of localized business strategy is a highly feasible mode of operation. Therefore, the general hotel chain model is a priority business method that better reflects service standards and service image.

\section{Staff Management System Function}

The WT standard in SWOT-AHP model indicates that high-tech techniques can be used to reduce the dependence on labor, that a one-time investment is convenient for long-term use, and that the quality of staff can be improved while reducing labor intensity. The specialized training for staff and the improvement of 
employee benefits are important factors in ensuring service quality. In our opinion, the most important aspect of the new hotel-style nursing home model is the use of high-tech IOT technology. However, these technologies depend partly on the operation and maintenance management by artificial. Therefore, the level of service can be further improved by selecting younger staff and improving their level of education and by adding new technology to the business model of a new hotel-style apartment nursing home. The professional technical training for employees can enhance their loyalty if the operating technology is only applicable to this nursing home, which can effectively prevent the loss of employees.

\section{Formulas and Equations}

The AHP application was put forward in the 1970s, and is an operation research decision-making technique that can solve real problems. Its core concept is to decompose different variables that affect one element into a judgment matrix by investigation and discussion, and then comparing the variables pairwise to determine the most influential elements. The AHP Analysis is carried out as follows:

First, we build the hierarchical model. We classify different elements into a hierarchy and annotate the subordination relationships between them. If some branches include too many sub-systems, we subdivide it.

Second, we compose the judgment matrix. The AHP analysis determines the most influential elements by comparing the variables pairwise, which is only possible when the differences between various influential elements are affirmed by composing a judgment matrix. After that, the results are compared according to 1-9 and the differences between the various influential elements will be clear.

Concerning the formula $A k=(a i j) n \times n, A k$ represents the judgment matrix, aij represents the large unit in line $i$, row $j$ of the judgment matrix, and $n \times n$ represents the order of the judgment matrix.

Third, we perform a consistency check. We normalize all the elements in formula $A k=(a i j) n \times n$, and the result is as follows:

$$
\bar{a}_{\mathrm{ij}}=\frac{a_{i j}}{\sum_{k=1}^{n} a_{k j}}(\mathrm{i}, \mathrm{I}=1,2,3, \ldots, n)
$$

Then, we add figures in every line of judgment matrix $A k$, and the result is as follows:

$$
\overline{w_{l}}=\sum_{j}^{n}={ }_{1} \quad \overline{a_{\imath \jmath}}(i=1,2,3, \ldots, n)
$$

After that, we normalize the above formula, and the result is as follows:

$$
w_{i}=\frac{\overline{w_{l}}}{\sum_{j=1}^{n} \overline{w_{J}}}(i=1,2, \ldots, n)
$$

Finally, we perform a consistency check by computing CR according to the following formula:

$$
\mathrm{CR}=\frac{\mathrm{CI}}{\mathrm{RI}}
$$

\begin{tabular}{|c|c|c|c|c|c|c|c|c|c|}
\hline $\mathrm{N}$ & 1 & 2 & 3 & 4 & 5 & 6 & 7 & 8 & 9 \\
\hline$\overline{\mathrm{RI}}$ & 0 & 0 & 0.58 & 0.89 & 1.12 & 1.24 & 1.32 & 1.41 & 1.45 \\
\hline
\end{tabular}

The value of RI is assigned according to Table 1 :

Table 1

Average Random Consistency Index

The formula for $\mathrm{CI}$ is as follows: 


$$
\begin{aligned}
& \mathrm{CI}=\frac{\lambda_{\max -\mathrm{n}}}{n-1} \\
& \text { wo so st wt } \\
& \text { wo }\left[\begin{array}{cccc}
1 & 1 / 5 & 1 / 7 & 1 / 3
\end{array}\right] \\
& \text { so } 5 \quad 1 \quad 1 / 4 \quad 3 \\
& \text { st } \begin{array}{llll}
7 & 3 & 1 & 5
\end{array} \\
& \text { wt }\left[\begin{array}{llll}
3 & 1 / 3 & 1 / 5 & 1
\end{array}\right] \\
& \mathrm{AV}=\left\{\begin{array}{l}
0.229 \\
1.100 \\
2.356 \\
0.492
\end{array} \quad \lambda=\left\{\begin{array}{l}
4.0246 \\
4.1825 \\
4.2222 \\
4.0344
\end{array}\right.\right. \\
& \frac{4.1159-4}{4-1}=\frac{0.1159}{3}=0.0386 \\
& \mathrm{CR}=\frac{0.0386}{0.96}=0.0402<0.1
\end{aligned}
$$

\section{Figures and Tables}

According to Wikipedia, SWOT analysis is a basic strategic planning method used to evaluate the strengths, weaknesses, opportunities, and threats involved in a project or in a business venture so as to make feasible strategies. It involves specifying the objective of the business venture or project and identifying the internal and external factors that are favorable and unfavorable to achieve that objective (Hill \& Westbrook, 1997). The technique is credited to Albert Humphrey, the founding father of SWOT analysis, who led a convention at Stanford University in the 1960s and 1970s using data from Fortune 500 companies. Specifically speaking, strengths refer to characteristics of the business or team that give it an advantage over others in the

\begin{tabular}{|c|c|c|}
\hline & Strength & Weakness \\
\hline Matrix diagram & $\begin{array}{l}\text { A mature nursing home system } \\
\text { Five-star hotel-style management, } \\
\text { IOT advanced technology }\end{array}$ & $\begin{array}{l}\text { Low salary } \\
\text { Much extra work make employees tired } \\
\text { The imperfect domestic medical pension } \\
\text { system }\end{array}$ \\
\hline Opportunities & SO & WO \\
\hline $\begin{array}{l}\text { Chain brand } \\
\text { Location } \\
\text { The initial stage of specialization policy in } \\
\text { pension related industries }\end{array}$ & $\begin{array}{l}\text { Standardizing operations by unifying } \\
\text { signing service contracts, icons, service } \\
\text { images and service standards } \\
\text { Localization and standardization based on } \\
\text { the differences of their characteristics }\end{array}$ & $\begin{array}{l}\text { Reducing cost effectively by applying } \\
\text { scale effect } \\
\text { Improving community infrastructures by } \\
\text { fully employing } \\
\text { Improving the income of nursing home by } \\
\text { satisfying the needs of the elderly from all } \\
\text { income groups }\end{array}$ \\
\hline
\end{tabular}
industry. Weaknesses are characteristics that place the firm at a disadvantage relative to others. Opportunities are external chances to make greater sales or profits in the environment. Threats are external elements in the environment that could cause trouble for the business. Generally, SWOT is carried out in the following steps: First, analyze business's external environments to find out opportunities and threats a business faces; Second, analyze business's internal factors to find out strengths and weaknesses a business possesses; Third, allocate external opportunities and threats with internal strengths and weaknesses.

Table 2

SWOT-SO, WO, ST, WT 
(Table 2 to be continued)

Threats

Low quality employees
ST

Establishing a training department to improve employees’ quality by regular training

Introducing advanced technology in IOT field, such as RFID technology, face recognition, GPIS positioning to build healthy big data

\section{WT}

Using advanced technology to reduce dependence on labors Using investment in the long term Improving employees quality while reducing workload Providing professional training and raising salary

\section{References}

Chen, C., Hu, Y. J., \& Wang, Y. T. (2012). The impact of population aging on health expenditure in China. China Health Statistics, (3), 420-430.

Dong, H. Y. (2011). Research on the construction of China's social pension service system. Beijing: China Social Science Publishing House.

Gong, Y. J. (2004). Home care for the elderly-community care services: Urban pension patterns in line with China's national conditions. Journal of Hehai University: Philosophy and Social Sciences Edition, (4), 72-74.

Gu, L., Zhou, Y., \& Yan, W. C. (2015). Research on nursing home chain business model relying on the community. Journal of Huazhong Agricultural University: Social Science Edition, 119(5). Retrieved from http://www.cqvip.com/QK/82116X/201505/665614266.html

He, J., \& Zhao, Y. B. (2013). Feasibility analysis of home-based community pension model. Market Journal, (1), 99-116.

Hill, T., \& Westbrook, R. (1997). SWOT analysis: It's time for a product recall. Long Range Planning, 30(1), 46-52.

Li, B., Zhang, K. T., Wang, H. T., \& Pang, T. (2011). Thoughts on the construction of basic pension service system. New Vision, (1). Retrieved from http://sociology.cssn.cn/xscg/zxwz/201103/t20110314_1986119.shtml

Li, C. Y., \&Yang, J. F. (2008). Discussions on the government's financial responsibility in the rural social endowment insurance system. Journal of Huazhong Agricultural University: Social Science Edition, (5), 10-14.

Liu, X. J. (2013). Community nursing home: Research on advantages, dilemmas and development strategies. China-today Forum, (9), 21-22.

Luo, G. C. (2011). Exploring the comprehensive service model of community care for the elderly in China's urban areas. Beijing: Social Science Literature Publishing House.

Policy Research Department, China National Ageing Committee. (2006). China population aging development forecast research report. Retrieved from https://wenku.baidu.com/view/7dc0a7125b8102d276a20029bd64783e09127d96.html

Tao, L. Q. (2003). Social welfare for the elderly in China. Beijing: China Social Science Publishing House.

Wu, H. P. (2010). Advantages and risk avoidance of chain operation. Business Economy, (7), 26-29.

Yang, S. Y., Wei, S. C., \& Guo, W. (2008). Chain management. Shanghai: Fudan University Press.

Zhao, L. X. (2004). Discussions on community construction and home-based community pension. Population Journal, (3), 34-40. 